Página inicial: 513 - Página Final: 533

Tipo de artículo: Investigación

\title{
Víctimas del conflicto armado en la ciudad de Medellín: una lectura estética de la participación política
}

\author{
Armed Conflict Victims in the City of Medellin: An Aesthetic Interpretation of Political \\ Participation
}

Recibido: abril de 2017 Revisado: mayo de $2017 \quad$ Aceptado:junio de 2017

${ }^{1}$ Psicóloga, Magíster (MSc) en Educación y desarrollo humano, y hermenéutica literaria, docente investigadora de la facultad de psicología, Universidad de San Buenaventura, sede Medellín (Colombia). Contacto:

Jolyn.castrillon@usbmed.ed $\underline{\text { u.cO }}$

2Psicólogo, Magíster (MSc) en Investigación psicoanalítica, docente investigador de la Facultad de Psicología de la Universidad de San Buenaventura, sede Medellín (Colombia). Contacto:

Andres.palacio@usbmed.ed u.CO

3Psicóloga. Facultad de Psicología de la Universidad de San Buenaventura, sede Medellín. (Colombia). Contacto:

fernandap19@hotmail.com

${ }^{4}$ Psicóloga. Facultad de Psicología de la Universidad de San Buenaventura, sede Medellín. (Colombia).

Contacto:

nancyalvarezal@gmail.com.

5Psicólogo. Facultad de Psicología de la Universidad de San Buenaventura, sede

Medellín. (Colombia).

Contacto:

santiagopgx-

27@hotmail.com
Por: Jolyn Elena Castrillon Baquero ${ }^{1}$, Andrés Felipe Palacio Pérez ${ }^{2}$, María Fernanda Gómez ${ }^{3}$, Nancy Stella Álvarez Álvarez ${ }^{4} \&$ Santiago

Paniagua García ${ }^{5}$

\section{Resumen}

La configuración de perfomancias ligadas a la práctica del plantón, como escenario de participación pública alude por un lado, a la función trágica del teatro al exponer como fenómeno político las desapariciones forzosas y el cuestionamiento del tipo de sociedad y valores que se construyen a su alrededor; así mismo, visibiliza una estética colectiva basada en lo afectivo como envoltura destinada a generar evocaciones emocionales en la esfera pública, y de esta manera ampliar el eco participativo de la organización que incide en la sociedad configurando la posibilidad de una sabiduría política, toda vez que expone la visión trágica de develar los sentidos de las historias singulares de cada familia; es lo que se evidencia en la compresión de los sentidos y significados que la Organización Caminos de Esperanza -Madres de la Candelaria - organización de madres víctimas del conflicto armado, en la ciudad de Medellín - Colombia.

Palabras clave. performance; víctimas del conflicto armado; reparación; participación; simbolización.

\begin{abstract}
The configuration of performance, linked to the practice of the sit-in, as the scenario for public participation, refers on the one hand, to the tragic theatre function by exposing as a political phenomenon, the enforced disappearances and the questioning of the kind of society and values, which are built around it. It also makes visible a collective aesthetic based on the affective as a cover aimed at generating emotional evocations in the public sphere and thus, expand the participatory echo of the organization, which influences society, setting up the possibility of a political wisdom, since it exposes the tragic vision of revealing the senses of the unique stories of each family, this is what is made evident in the compression of the senses and meanings of "Roads of Hope Organization" The Mothers of La Candelaria," which is an organization of mothers of victims of the armed conflict, in the city of Medellín, Colombia.
\end{abstract}

Key words: Performance; Victims of the Armed Conflict; Indemnity; Participation; Symbolization. 


\section{Introducción}

Los adivinos se tienden en el suelo, pegan a él el oído, auscultan como médicos el pecho de la tierra sumida en su letargo. El tiempo reanuda su pulso al compás del reloj de Dios. E1 péndulo del mundo es el corazón de Antígona. Yourcear, 2012

El presente estudio tiene como escenario el plantón de la organización Caminos de Esperanza Madres de la Candelaria, organización social de víctimas de la violencia política en Colombia, quienes por casi 20 años han trabajo continuamente en la denuncia y reclamo de sus seres queridos desparecidos. Como movimiento social que escenifica sus prácticas en el espacio público, y ello cobra consecuencias en las dinámicas propias de la ciudad, atendemos la lectura de esta organización como proceso de acción colectiva, movilización de recursos materiales y simbólicos, más su construcción como actores sociales que devine en una identidad subjetiva de ciudadanía participativa.

De allí, que la pregunta que se suscita es por la compresión de los sentidos y significados que las madres han construido sobre su participación en el escenario público, en este caso en el plantón, escenario performativo de su accionar colectivo a partir de una práctica simbólica cooperativa y de apoyo mutuo para expresar su dolor (Ibarra, 2011). Esto requirió una mirada intertextual de sus prácticas, como una performancia crítica que hoy, en un contexto poscolonial, favorecen el abordaje de fenómenos sociales y políticos (Vasilachis 2015).

Su lectura parte de una perspectiva fenomenológica-hermenéutica, la cual busca develar los sentidos construidos que los actores generan a partir de su propia experiencia. Los aportes teóricos que acompañan la discusión discurren a modo de intertextos, como juego en que se va determinando que texto sigue al otro, en la producción analítica. Entre ellos, algunos referentes investigativos sobre los movimientos sociales y sus discusiones en torno a los conceptos de subjetividad política, la cual nos abre el interés sobre el escenario de lo público.

Entrados en el terreno de la participación, este es ampliado con el criterio de lo estético - político, aportado por filósofo Jacques Rancière, y traducido al hispano por Arcos- Palma (2009), dado que expone una redefinición de la política, centrada como dispositivo y alejándolas de las élites propias disciplinares al ponerla al servicio de lo real de la sociedad. Seguidamente, como enfoque teórico que guío la matriz analítica y respaldó la compresión del trabajo de campo, se aproximaron los aportes de la semiótica de Roland Barthes (1970-1989) y su consecuente reflexión de la imagen a través de la fotografía.

Por último, y continuando con la línea intertextual referida, se asocia la lectura panorámica del género trágico y su expresión en el teatro ateniense. Esta realización literaria, comentada por la filósofa española Rocio Orsi (2007), permitió una relación interpretativa del plantón en el escenario público, como escena teatral y el desarrollo analítico del mito trágico de Antígona, consecuencia absoluta en la lectura performativa de este estudio.

La revisión teórica enlazada constantemente con el trabajo de campo, desplegó la metodología a través de la estrategia de la fotoetnografía (Luna, 2009) y la fotografía relatada, a partir del juicio de Roland Barthes (1989) sobre la imagen. Así pues, el juego de la intertextualidad puede resultar oportuno, si lo que se trata es explorar y aproximar lo que se ha denominado la dimensión estética de 
la investigación basado en las artes que se nutre de la imaginación, las experiencias de las comunidades, y una percepción de los fenómenos con un alcance emotivo (Finley, 2015).

Los anteriores elementos fueron analizados y discutidos mediante el ejercicio de categorización y producción orientado por la teoría fundada que generó los siguientes hallazgos: La importancia del plantón como estética de la ciudad, toda vez que se escenifica la participación política, como acto colectivizado teñido de dimensiones afectivas, a partir de dolor de la desaparición y la esperanza compartida por el regreso de sus familiares. Dicha acción participación, ahora conlleva nuevos roles participativos; entre ellos, la condición de mujeres determinada inicialmente en lo doméstico del campo colombiano - el oikos- que hoy trasega de lo privado a lo público, cuando ocupan la polis- la plaza pública- y como el mito trágico de Antígona denuncian y reclaman a sus seres queridos desaparecidos, tratando de ser leales a la ley de divina, y a ley de la sangre.

Por último y tal es la metonimia del plantón, como la representación teatral de Sófocles, que caracterizan una performancia alusiva a la función trágica del teatro: el develamiento de un fenómeno político que precisa una revisión del tipo de sociedad y valores que se construyen. Del mismo modo, una performancia que configura la posibilidad de una sabiduría política, al exponer la visión trágica que sustenta la pregunta del sentido: el ¿quién soy?, develamiento posible si se sale al encuentro público, con las acciones de los otros y sus mundos diferentes

A continuación de describen el contexto de los antecedentes y los principales aportes teóricos relacionados con el estudio.

\section{Contexto del conflicto en Colombia}

En el contexto del conflicto armado y violencia política que ha padecido Colombia desde mediados del pasado siglo, se han causado miles de violaciones de derechos a la población civil colombiana. Es posible que los casos registrados sean inferiores a las dimensiones reales del conflicto; sin embargo, el Centro Nacional de Memoria Histórica (2013) describe las siguientes estimaciones:

Al 31 de marzo del 2013 el Registro Único de Víctimas - RUV - de la Unidad de Atención y Reparación Integral a las Víctimas reportó que 166.069 civiles fueron víctimas fatales del conflicto armado desde 1985 hasta esa fecha. Sin embargo, este balance es parcial debido a que el marco legal solo reconoce a las víctimas a partir del $1^{\circ}$ de enero de 1985 , lo que excluye a 11.238 víctimas documentadas en la base de datos del GMH entre 1958 y 1984.4 Así mismo, es importante señalar que en el RUV no están incluidos los combatientes muertos en las acciones bélicas. De acuerdo con la investigación del GMH, entre 1958 y 2012, murieron 40.787 combatientes. Es así como al compendiar estas cifras, es posible afirmar que el conflicto armado colombiano ha provocado aproximadamente 220.000 muertos. De estas muertes el 81,5\% corresponde a civiles y el 18,5\% a combatientes; es decir que aproximadamente ocho de cada diez muertos han sido civiles, y que, por lo tanto, son ellos — personas no combatientes, según el Derecho Internacional Humanitario— los más afectados por la violencia (p.32).

Esta extensa afectación a la población colombiana, ha conducido a la creación de múltiples organizaciones colectivas de víctimas, quienes demandan en la escena pública, mediante distintas estrategias de acción, el restablecimiento de sus derechos vulnerados, como las acompañadas por el Grupo de memoria histórica para el informe Memorias en tiempo de guerra (2009), para el que fueron 
reseñadas 198 iniciativas de memoria efectuadas por organizaciones de base, ONGs, comunidades religiosas, grupos étnicos, organizaciones de víctimas, organizaciones de mujeres y movimientos por la paz, entre los cuales se encuentran las Madres de la candelaria.

\section{Panorama de los Movimientos de no violencia y la participación política}

La psicología política, en especial en América Latina, y en Colombia (Sabucedo, 2010 Molina, 2005; Botero, 2008; Díaz, 2012; Estrada, 2011; Parisí \& Cuello, 2012), se ha preocupado por revisar y atender los procesos comunitarios a partir de los movimientos de resistencia en la lógica especialmente de la no violencia.

La característica de no violencia es llamativa, porque recrea las condiciones, imaginarios y acciones de la vida cotidiana que envuelven a los jóvenes y mujeres como principales actores y protagonistas de estos movimientos. Algunas de las conclusiones de estos estudios, han derivado nociones de interés contemporáneo para las ciencias sociales, que en general no se restringe a una sola disciplina, lo que favorece una lectura mucho más compleja de los grupos humanos y formas de actuación social. Una de estas nociones es la subjetividad política que emana de la subjetividad social (Díaz y González, 2005), dimensión reconocida en los procesos de la cultura en la que el sujeto en tramas y pliegues relacionales desarrolla su realidad humana como realidad social. Solo es contemplarlo desde la idea de Castoriadis (1992) citado por Tello (2003), para denotar la imbricación del fenómeno: "Lo psíquico y lo social son, por un lado, radicalmente irreductibles, lo uno a lo otro y, por otro lado, absolutamente indisociables, lo uno e imposible sin lo otro" (p.16).

De momento lo que debemos reparar es el interés por la subjetividad política, que nos ofrece un panorama sobre la lógica de cohesión de los movimientos sociales. Tras la revisión de Díaz y Alvarado (2012), esta forma de subjetividad desarrolla una acción reflexiva que los sujetos realizan sobre sí mismo y sobre lo que le es impuesto en el orden social, lo instituido, de tal manera que se produzcan creaciones propias, lo instituyente, tanto en las relaciones del entre nos como en las relaciones de los sistemas de organización social, todo ello centrado en el espacio público.

Seguidamente la reflexión de lo público es evidente, porque pone a transitar los asuntos que concierne al nos, nos ayuda ampliar la expresión nos, si retomamos la relación ofrecida por Vélez (2011), con el término de acogida, entendiéndose esté como un encuentro, el cual no es solo cruzarse con alguien, o simplemente toparse con su cuerpo; el autor, lo eleva a los significados de devenir, mudar de estado, de acción, de relación. Como expresión que abarca lo que: "se basa en, trata de, y nace en” (Díaz, 2003, p.51). El autor toma de referencia la teoría política de Hannnah Arendt, acudiendo a la pluralidad como condición de la acción, en tanto funge como espacio de aparición, donde junto a otros se pueden discurrir y debatir asuntos comunes. A saber:

El espacio de aparición cobra existencia siempre que los hombres se agrupan por el discurso y la acción, y por lo tanto, precede a toda formal constitución de la esfera pública y de las varias formas de gobierno, o sea, las varias maneras en la que se puede organizarse la esfera pública (Arendt, 2005, p. 225).

Aquí surge una relación importante entre el entre nos y la participación política, toda vez, que el espacio de aparición se hace entre otros (Butler, 2011). La expresión participación política solo aparece tímidamente alrededor de los años 80, y tuvo su relación estrecha tras el fenómeno del voto electoral. 
Los estudios que ampliaron esta visión tienen que ver con formas alternativas de participación y se relacionaron con los fenómenos de resistencia y la existencia del conflicto como parte de la vida cotidiana (Parisí y Cuello, 2012).

En la contemporaneidad, los elementos símbolos que se apropian en las formas de participación, ya no apuntalan necesariamente en la afiliación de un partido político, sino más bien aparece una faz expresiva que, como afectividad colectiva, viene siendo analizado por la psicología social, en el horizonte de los movimientos sociales y la participación. Estrada (2011), ofrece un contexto desde la referencia de Fernández Christlieb, al decir:

Ahora, Fernández (2003) también es claro en señalar que las emociones o la afectividad, es aquella parte de la vida que antecede y/o excede al lenguaje mismo, y en gran medida desempeña el papel de movimiento social; pues altera, transforma y mueve determinadas estructuras, instituciones o procesos sociales; por ejemplo, la cultura (p.24).

Y luego concluye: "Los sentimientos aglutinan a los miembros de las colectividades y agrupamientos políticos, en torno a proyectos específicos con los que se identifican, no sólo ideológicamente, sino como causas inaplazables" (p.24).

Villa Gómez (2016) afirma que

"Estas experiencias dan cuenta de formas a través de las cuales la gente no es simplemente un sujeto pasivo de acciones estatales, de ayudas externas, que profundizan su condición dependiente y pueden instalarle en una identidad de victima; sino que evidencia su inmensa capacidad para resistir y reconstruir, para mantener su dignidad e incluso para desarrollar acciones paralelas que les permiten trascender el lugar de la víctima y empoderarse como sujetos de derecho, como actores sociales protagonistas de su propio desarrollo y en la superación de las consecuencias que la guerra le dejó" (p. 454).

A medio camino podemos concluir, y para este caso, que la participación política se asume como prácticas en un conjunto de acciones relacionales y afectivas, se desenvuelven ocupando los entramados de la vida social dentro de una comunidad, la cual busca una identidad participativa a través de la asunción de fines colectivos. Ahora, cabe la pregunta: ¿la organización Madres de la Candelaria, ha desarrollado a través de la práctica del plantón una participación política envuelta en afectos compartidos ligados al duelo?, ¿y tras ello la organización plasma su acción estética?

A riesgo de responder lo anterior, surge la necesidad de ampliar el abordaje de la afectividad en la participación del plantón, considerando la lectura estética. Dicha lectura será entendida en principio, como las formas sensibles que configuran las actuaciones y cobran vida en la dinámica relacional de los movimientos sociales.

\section{Participación política y expresión estética}

En consonancia con la reflexión de Jacques Rancière, sobre la idea de sensorium recobrada de Merleau Ponty, al decir: "el campo sensorial contempla el cuerpo y el mundo en el ser-para-sí y en el estar-en-el-mundo” (Arcos- Palma, 2009, p.144), podemos acercar la expresión de lo sensible en las manifestaciones de los movimientos y su participación política. Arcos- Palma nos acerca a los análisis del filósofo francés, partiendo de la posición en que este redefine la estética no solo perteneciente al orden sensible sino al social y por ende político. 
Es decir que la estética, en cuanto disciplina filosófica, tiende un puente entre las formas sensibles -el Arte con mayúscula- y la vida misma, la cual encuentra su mayor expresión en las esferas de lo político y lo social (Arcos - Palma 2009, p.143).

Son pertinentes los aportes de Rancière, para el análisis de la lectura del plantón, ya que de manera intencional hemos primado la versión del teatro ateniense como modo para interpretar el escenario del plantón, y en cuya acción pública es posible reconocer la llamada redistribución de lo sensible la cual es lo común y lo compartido de las voces que se escenifican en cada presentación del plantón. En la presentación de los hallazgos se exponen estas formas de lo sensible, que emergieron a través de las fotografías relatadas de las participantes.

\section{La organización y el plantón Caminos de esperanza Madres de la Candelaria}

La organización fue fundada en marzo de 1999, durante un periodo crítico de la guerra, conformada en sus inicios por un grupo de familiares de policías y soldados secuestrados por las guerrillas, y poco a poco se fueron sumando familiares de víctimas de desaparición forzada, asesinato, desplazamiento, creciendo el movimiento a medida que se intensificaba la guerra. (Martínez y Londoño, 2012). Actualmente las integrantes del movimiento son en su mayoría mujeres, amas de casa de origen campesino, oriundas de diferentes regiones de Antioquia. (Giraldo, Toro, Estrada \& Mejía, 2015).

Sin lugar a dudas y como ya se ha descrito, una de las acciones visibles de la organización es el llamado plantón. Esta actividad es vital para el grupo ya que fue la primera experiencia pública en la denuncia y reclamo de sus familiares, sucedió en el mes de marzo de 1999, y a la fecha ha continuado como gesto de resistencia social ubicándolas en la línea de movimientos sociales femeninos de América Latina, con empoderamiento en la participación de la agenda política del país. Lo anterior se constata con la presencia de la organización, en los diálogos de la Habana, como representantes de la sociedad civil y como organización de víctimas. Estos diálogos han sido el centro neurálgico del actual panorama colombiano, donde se han construido el proceso y los acuerdos de paz, entre el gobierno del presidente Santos (2014- 2017) y el grupo insurgente FARC- EP.

En Colombia la organización Caminos de la esperanza Madres de Candelaria, ha sido investigada por diversas disciplinas de las ciencias sociales y humanas, sociólogos, comunicadores, periodistas y psicólogos del campo psicosocial esgrimen una serie de reflexiones que giran principalmente a visibilizar las acciones de transformación social a partir de las discusiones de la memoria social, ciudadanía y participación política que dinamizan esta organización.

Resultados como los expuestos por la periodista Tamayo (2013), en el estudio sobre esta organización refiere:

El plantón de las Madres es una acción colectiva que se constituyó en estrategia de comunicación con alta efectividad debido a su prolongación en el tiempo, ya que se ha mantenido desde el inicio del movimiento. Su localización, en un lugar cargado de historia y simbologías de poder en el centro de la ciudad de Medellín, responde a una propuesta consciente y racional desde la comunicación, ya que el fin último del movimiento es informar a la sociedad sobre la existencia de las mujeres-madres como víctimas en razón de la desaparición forzada de sus familiares.(...)En la manifestación semanal con el plantón, la Asociación logra hacer surgir y reforzar la empatía y solidaridad de la ciudadanía con el dolor y la lucha de las Madres (2013, pp.87-88). 
Por su parte Ibarra (2011), da cuenta de las múltiples acciones de la Madres de la Candelaria en el reclamo y búsqueda de sus seres queridos en una apuesta por la libertad y celeridad en los juicios de justicia y paz. En su estudio refiere:

Utilizan los recursos de cooperación para investigar y producir informes, videos, cartillas y campañas, que constituyen iniciativas textuales para documentar su memoria. En los Actos públicos simbólicos se incluyen performances, galerías de memoria (fotografías, nombres, objetos personales de las víctimas), vigilias, construcción de monumentos y esculturas, pintura de murales y vallas, montajes de coreografías, carteles testimoniales, silencios prolongados y abrazos. Las vigilias incluyen rituales, cantos, proyección de videos, cuenteros y música con contenido social. Estas mujeres llevan la memoria a cuestas: "Se trata de una "performatividad" que pone en escena un dolor que no cesa. (Uribe, 2009, p.49), luchan por preservar la memoria personal y colectiva de silencio y dolor, a pesar de la impunidad en sus casos y de las amenazas que reciben (Ibarra, 2011, p. 147).

Los resultados investigativos desde una visión psicosocial, sobre esta misma organización realizada por Castrillon, Marín \& Villa (2016) exponen:

En particular la Asociación Caminos de Esperanza, Madres de la Candelaria, se presenta como el grupo secundario que posibilita el apoyo mutuo a las familias; éstas se vinculan con la asociación, principalmente, con la acción de visibilizar sus seres queridos, los cuales, ya desaparecidos o muertos, hacen presencia a través de las voces de familiares en los diferentes actos públicos. El Plantón es uno de ellos, convirtiéndose en el principal escenario donde los lazos de solidaridad se estrechan a través de la exposición de fotografías y consignas que las madres claman sobre sus desparecidos en plena plaza pública: (...) (p.418).

Igualmente, el plantón de las madres ha cobrado interés por áreas escénicas y de la plástica. Así, el trabajo de Ileana Dieguez, en su libro Cuerpos sin Duelo (2013), expone las relaciones entre cuerpo, prácticas artísticas y duelo. Esta filosofa se ocupa de retratar desde una línea estética la violencia que ha minado comunidades en México y Colombia. Su estudio hace énfasis según Nieto (2014) en exponer:

Una reflexión sobre el modo en que la violencia ha penetrado las representaciones estéticas y artísticas, ha transformado nuestros comportamientos y visualidades en el espacio real, ha intervenido los cuerpos y generado una nueva construcción de lo cadavérico y se ha apropiado de procedimientos simbólicos y representacionales para transmitir mensajes de terror (Diéguez, 2013, p. 30 citado por Nieto, 2014, p.1).

Las Madres de la Candelaria, al igual que un grupo de mujeres de México, a quien la autora las describe en orfandad son predecesoras de Antígona, el mito de Sófocles que se recrea en esta visión estética, y que para el análisis de este estudio surtió en una relación inesperada, pero oportuna que ofrece un collage con juegos intertextuales de naturaleza estética, en este caso la literatura que media la lectura del fenómeno. 


\section{El plantón en la Plaza Pública: performancia del teatro ateniense y la tragedia de Antígona}

La exposición del plantón en el parque de Berrío, propician un espacio de resistencia que, junto a sus vendedores, transeúntes y fachadas, transforman la dinámica rutinaria de la plaza pública, en una especie de teatro ateniense que funge la presencia del coro - el coro en la tragedia griega tiene como función señalar una función de conjunto sobre la acción trágica, y se pone en dialogo con los personajes detallando el conjunto de la obra- ante los ciudadanos. Cuando las madres expresan en uno de sus pregones: "Este es nuestro dolor, ¿cuál es el tuyo?" manifiestan una tragedia como hecho y drama de la ciudad".

El teatro ateniense, ya sea el drama trágico o satírico, tiene un carácter popular y religioso: "Es, pues un fenómeno político desde todos los puntos de vista: no solo tiene un trasfondo político, sino que es, sobre todo, parte de la vida de la pólis" (Orsi, 2007, p.33). Seguidamente la autora enlaza el género trágico aduciendo su necesidad en la construcción histórica de las polis ateniense. Esto es de suma importancia en la lectura del fenómeno de violencia política que nos concierne en el estudio, ya que aporta una reflexión histórica y estética del carácter político que se forja un país, de los valores estéticos ligados a la socialización política.

La tragedia es parte activa de la pólis no solo ( aunque también) porque la polis está presente en todas sus fases (en la representación, en la organización, en el contenido mismo de la obra), sino porque es una actividad que contribuye a crear la unidad misma de la polis, propiciando una toma de autoconciencia, ya sea en los ciudadanos en su calidad de ciudadanos (al cobrar conciencia de su libertad, que consiste básicamente en su capacidad para participar en lo público), ya sea en toda la ciudad como ciudad (pues la tragedia, como se verá, representa, cuestiona y celebra la polis de Atenas).

\section{El mito trágico de Antígona}

La obra se abre con un enfrentamiento entre las hijas de Edipo, Antígona e Ismene. Por su discusión conocemos los antecedentes del drama: que la doble muerte de sus hermanos, Eteocles y Polinices, ha convertido a su tío Creonte en un nuevo gobernante de Tebas y nuevo cabeza de su familia; y a las dos hermanas, a su vez, las ha convertido en únicas supervivientes de la familia de Edipo. También nos llegan noticias del edicto de Creonte: en calidad de jefe de la ciudad ha decidido que el cuerpo de Polinices quede abandonado como pasto para las fieras. Y nos enteramos de la resolución de Antígona de desobedecer este edicto así como de la renuncia de Ismene, lo que causa la ruptura entre ellas. Así, desde el comienzo se plantea la confrontación elemental entre el acatamiento de la autoridad política y militar frente a la rebelde devoción filial y religiosa (Orsi, 2007, p.200).

Se conoce luego la muerte suicida de Antígona, a partir del edicto de ejecución por parte de Creonte. Su prometido Hemón trata de vengarla y, al no conseguirlo, se da muerte y yace con su prometida en la cueva. La obra termina dedicada a las intricadas relaciones entre sabiduría y felicidad. Por ello Antígona se ha descrito como una tragedia que expone una nueva sabiduría política, lo que fue objeto de análisis y lectura particular en este trabajo, desarrollada como acción política y participativa dada a partir de la visión por la visión trágica.

Se reconoce a Antígona como la tragedia antigua más representada y reescrita en la modernidad, una obra leída y vista como un drama político. Es plausible una lectura que, desde la visión trágica, no alejada del fenómeno moral frente a la autoridad, se relacione con el accionar en lo público, y enfatice 
que, además, y sobre todo en esta acción, específicamente política, se reconozca la idea de sabiduría política. Por ahora podríamos decir, que tal sabiduría va estrechamente relacionada con una visión trágica, toda vez que el mundo que responde a esta visión es una constante construcción de mundo, no aislada, sino acompañada, al salir al encuentro de otras construcciones diferentes a las propias (Silva, 2005).

\section{La semiótica y la fotografía como arte performativo del plantón}

La teoría semiológica inicialmente referenciada por Ferdinand de Saussure (1908), es el amplio horizonte conceptual donde se aproximaron las lecturas iniciales del estudio, en tanto las preguntas se limitaban a interrogar un escenario como se ha planteado, lleno de símbolos, que requerían ser provistos. Guiraud (1972), describe en su texto, La Semiología, la citación frecuente que Saussure hace sobre el concepto.

La lengua es un sistema de signos que expresan ideas, y por eso comparable a la escritura, al alfabeto de lo soros modos, a los ríos simbólicos, a las formas de cortesía, a las señales miliares, et., etc. Sólo que es más importante de todos esos sistemas. Se puede, pues, concebir una ciencia que estudie la vida de los signos en el seno de la vid social. Tal ciencia sería parte de la psicología social, y por consiguiente de la psicología general. Nosotros la llamaremos semiología (del griego semeión "signo" Sausurre (citado por Guiraud, 1972, p.7).

La aproximación semiótica de Roland Barthes, consiste en exponer sobre la no naturalización del signo, en comprender a estos como fenómenos culturales e históricos, de usos de época, no universales, para lo cual introduce el mito, comprendiéndolo como el modo de significación de una forma, tomando así el discurso escrito, la fotografía, el cine, el reportaje, el deporte, los espectáculos, la publicidad, etc., como soportes del habla mítica (Zecchetto, 2008).

La expresión de la fotografía como texto analógico de la realidad producirá efectos determinantes en las fotografías tomadas del plantón ya que no nos enfrentamos a un plano viviente, y al fotografiarse ocurre un desconcierto de la realidad tiempo- espacio, en tanto se instala una conciencia de no estar allí- estando. Ejemplo de esta labor fotográfica la ofrece el periodista y fotógrafo, Jesús Abad Colorado, quien acompaña a las victimas colombianas en un ejercicio de memoria, tras las pérdidas de sus seres queridos a través de la fotografía documental (Colorado, 2016). Experiencia de memoria, en el plantón, que tiene que ver con un tiempo inmediato al ver los rostros que exhiben las madres de sus desparecidos y, a la vez, anterior por a la ausencia del ser querido. De acuerdo con Barthes (1989) se produce una paradoja del aquí y el antes que será analizada en la discusión del estudio.

En su obra La Cámara Lucida, Barthes (1989), nos provee de dos elementos más, que favorecen una lectura interna de la fotografía y el efecto particular que produce sobre el observador. Plantea que es lo particular y la esencia de la fotografía al hablar del Stadium y el Punctum. Ambas hacen una coexistencia y constituyen los elementos que animan la fotografía. El Stadium, que puede compararse con el mensaje connotado ya descrito, comporta un saber cultural.

Por otro lado, el punctum lo describe como aquello que nos punza y divide el staudium. "El punctum de una foto es ese azar que en ella me despunta (pero que también me lástima, me punza)" (Barthes, 1989 , p.65). Es un detalle que el ojo precisa y que no corresponde con una composición anticipada 
del fotógrafo "Por fulgurante que sea, el punctum tiene, más o menos virtualmente, una fuerza de expansión. Esta fuerza es a menudo metonímica (Barthes, 1989, p.90).

Ambos elementos, Stadium y el Punctum, son referentes en la lectura de las fotografías en un entramado de tiempo, fechas y recordaciones que las madres narraron en las fotografías relatadas y que luego de materializadas en la descripción de categorías pasan a ser comentadas en el apartado de los hallazgos.

\section{Metodología}

El respaldo de este tipo de investigación resulta del reconocimiento de la complejidad en los cambios sociales, políticos y filosóficos contemporáneos, además, del reconocimiento de realidades a partir de las comunidades y prácticas discursivas (Finley, 2015; Chase, 2015; Atkinson y Delamont, 2015; Harper, 2015). Esto nos expone en el lugar del giro narrativo del discurso de las ciencias sociales, que comprende la realidad como entidad situada, susceptible de ser interpretada desde diferentes códigos lingüísticos, desligada de concebir categorías fijas y universales. Basa la creación y promoción de los textos hermenéuticos para un dialogo que desdibuje los límites entre investigadores, participantes y lectores. El texto, entonces, se define en sus términos más amplios e invoca toda la acción para ser leídas. Nos basamos entonces en la intertextualidad: "Un texto juega con el siguiente texto; es decir, el juego de la intertextualidad es el proceso de determinar que texto refiere a otro texto durante el proceso de producción cultural” (Barthes, 1970-1974 citado por Finley, 2015, p.122).

Esta primera referencia pone en consideración la perspectiva de estudio, una lectura próxima a la estética donde los métodos literarios, performativos y visuales permitieron dar cuenta de la autoexpresión política de la organización. Una propuesta basada en las artes (Rodriguez, 2006; Vasilachis, 2015; Harper, 2015).

Además, como estrategia metodológica para acceder al plantón, en cuanto escena teatral, y centrar la dinámica, allí, en su momento inmediato se optó por la foto etnografía, la cual de acuerdo Ulf Wuggenig (1990 citado por Luna 2009) su intención es mostrar el rol activo de los participantes. De esta manera, y luego de que el grupo de mujeres se instalará en el atrio de la iglesia de la Candelaria y entrarán a la escena a modo del coro, se desarrollaron las tomas fotográficas para un total de 102 piezas, las cuales se agruparon intencionalmente en tres galerías: El plantón, La obra teatral y el escenario público, para un total de 90 fotografías.

Luego, y a través de las exposiciones de las imágenes, las madres desarrollaron fotografías relatadas, las cuales fueron narraciones sobre acontecimientos familiares, sobre la pérdida de su ser querido, sobre su vida en el plantón y del escenario de la plaza Berrio.

Tras la recolección de los datos, se pasó a la codificación en el software Atlas ti V.6, siguiendo las pautas de Strauss \& Corbin (1998) para el desarrollo del proceso analítico de segmentación, conceptualización e integración de los datos. Se codificaron tanto la imagen fotografías como los relatos, generando la fotografía relatada dispuesta, como un nuevo documento de la misma unidad hermenéutica; la cual también codificada y consignada en una matriz permitió hacer todo el proceso de los diferentes tipos de codificación. 
La codificación abierta se realizó al mismo tiempo que el microanálisis, en los cuales se examinaron las relaciones entre relato y fotografía. Estos fragmentos fueron analizados para abstraer temas centrales y categorías que emergieron. Se obtuvieron 86 códigos, que a su vez produjeron (2) dos categorías descriptivas: Afectos y rostros compartidos: Performatividad polar en el plantón y Sensorialidades participativas. Los códigos pertenecientes a estas categorías, se reagruparon en (1) una subcategoría axial: Historias de un Álbum familiar, la cual mantuvo relaciones de dependencia reciproca con las categorías iniciales y cuyo tejido dotaron de significación a la categoría emergente y conclusoria de este estudio: Teatralidad en el plantón: Antígonas de la Candelaria y la sabiduría política.

\section{Resultados y discusión}

\section{Afectos y rostros compartidos: Performatividad polar en el plantón}

Las participantes expresaron en las fotografías relatadas, la percepción emotiva de sus propios rostros en el plantón, dichas percepciones entendidas como performancias fueron luego narradas dando cuenta de detalles en su mirada subjetiva. El puctum, tal como lo indica Barthes (1989)se asigna como un elemento peculiar que produce un valor emotivo y es referenciado por el lector como aquello que le significa de manera relevante. "Ahí está la paisa como esa señora vea como esta cabesi agachada pensando ahí tal vez está pensando en ese momento" (P1 70:70). El relato describe una de las primeras voces de las participantes al mirar la fotografía y fijar su mirada en un punto específico de esta.

A partir de allí, los diversos puctums se congraciaron con la atmosfera que envolvían los rostros: la experiencia de duelo. Acontecimiento que no fue posible de separarse del contexto de reclamación en el platón y la emotividad que surgió entre ellas. "Se le nota una amargura siempre como una amargura" (P1 33: 33). Sin embargo, la interpretación de las participantes al ver los rostros se presenta como un juego de diversos matices, y la emotividad de los rostros cobra diversos juicios. "Un rostro de total derrota, yo pensaría que es una derrota completa es como si de pronto el caminar de ella de haber renacido volviera a caer otra vez en ese vacío de no saber qué voy hacer, para donde voy" (P6 60: 60). La anterior expresión da cuenta también de la pérdida que hace cuestionar la existencia, en términos de un camino que queda interrogado.

En contraste con lo anterior, las madres expresaron también emotividad en otro rostro que supera el drama. Entre ellas se reconocen aquellas que han podido, a partir del grupo, alcanzar la tranquilidad, construyendo la esperanza como un estado de ánimo. "Y ahí mirarla en esa foto, en esa foto a ella es porque ella era una, era una, era como esa esperanza que ella tenía que era aquí haberle encontrado sanación en su sanación y paz interior en su corazón porque ahí ella está muy tranquila" (P6 65: 65).

La escenificación pública del dolor vuelve a señalar su importancia, toda vez que la palabra es un vehículo para resignificar y evocar la memoria desde la instancia simbólica, cómo nos configuramos y qué futuro nos es posible después de ser narrados.

Al congregarse el grupo, sus relatos conjugaron expresiones polares, es decir: aquellas que detentaban oposición, tal como se describen en los anteriores relatos, posiblemente porque emergió la singularidad de cada historia vivida y en ella se plasma, al decir de Díaz, retomado a González Rey (2005): la subjetividad individual; la cual, como pliegue junto a la subjetividad social, son desdoblamientos subjetivos constituyentes del ser humano. De esta manera se integraron múltiples 
sentidos subjetivos: [...] "aparecen como la combinación de emociones y procesos simbólicos que se desarrollan alrededor de la experiencia cultural definida [...] (p. 20).

Al tiempo de la experiencia subjetiva individual, las madres expresaron también en los rostros fotografiados un sentido plural de sus emociones. Una de ellas relata "Porque por mucho que uno se ría no, no, no, no, siempre se le nota algo, exactamente, que hacemos como el payaso reímos para no llorar" (P6 20:20). Nuevamente se denota no solo lo polar: entre la risa y el llanto, sino que se plasmó el sentimiento colectivo: "el hacemos" del relato, conjuga un nosotros. Aquí yace una relación importante entre emoción y el escenario compartido. Estrada (2011) comentado a Fernández Christlieb (2003), expresa como el autor atiende a las emociones y las pone en relación con los planteamientos de la subjetividad: "De esta manera entonces, las emociones se articulan con los sentidos subjetivos que configuran la subjetividad social, de lo que se infiere también, que sirven de motor que moviliza la subjetividad política” (2003, p. 24).

Lo que resalta es el conjunto de rostros provistos de afectos y, a su vez, de relato que, como discursos, devela la acción de las participantes y se enhebra en tramas intersubjetivas (Eco, 2012). Lo anterior indica que las interacciones son el inters-est, según Arendt (2005, p.211), no como lo que resta entre los sujetos, sino como un mundo que subyace entre ellos. Entre los intersticios de los rostros, y las voces encontradas en las fotografías relatadas, se abrió un mundo performativo donde yacen las emergencias de los afectos y sentimientos compartidos de la organización a partir de su vivencia continua en el plantón.

\section{Sensorialidades participativas}

La instalación del plantón cada 8 días por parte de la organización hace aproximadamente 20 años, ha permitido el desarrollo de una práctica participativa no solo constante, sino con anhelo de reconocimiento. A partir de las fotografías del plantón en cuyas imágenes manifestaban sus consignas un participante relato: "Para que nos conozcan que somos una organización muy grande para dar ejemplo a todo el país y que reconozcan que hacemos las madres de la candelaria hablar mucho de la paz y de la reconciliación que no podemos vivir odiando a todas las personas" (P9 145: 145).

Tras la necesidad de verse como ejemplo, el grupo opera con la finalidad de unas metas comunes, esto las ubica en el plano de lo público y en consecuencia produce efectos. Primero, como protagonista en el reclamo de sus garantías frente al Estado de Bienestar; "Entonces eso es también un acto de resistencia” (P13 33: 33). Y segundo, en la consecución plena de derechos civiles, sociales y políticos. Otra participante relata acerca del plantón: "Yo diría que eso también es una denuncia pública porque es que primero a uno le daba pena ir a denuncia y ahora uno va y lo hace en lo público" (P13 33: 33).

Ahora, la importancia de lo público significa todo lo más en la participación. Este es el sello que la organización impone a su dinámica, desde las actividades que realizan a partir de las convocatorias por parte de los entes institucionales, hasta las movilizaciones no convencionales que se derivan en acciones civiles. La organización muestra un grado de autonomía importante en la calidad de lo público que yace en su participación. La palabra vehiculiza la organización y como plantea Habermas (1996), citado por Botero, Torres y Alvarado (2008), "la participación se plantea como mediación comunicativa en una red de pluralidad de espacios no necesariamente institucionalizados u organizados en lo formal” (p.575). Esto coincide con Nora Rabotnikof (1995) citado por Sánchez (2013) al definir: el espacio público como: 
Red de procesos comunicativos, autorregulados, sostenidos por organizaciones fluidas, horizontalmente interdependientes, de naturaleza más inclusiva y de forma más o menos discursiva, que se hallan en oposición a las iniciativas que emanan de organizaciones que intervienen en un espacio público dominado por los medios. (p. 71)

Si bien es notable la idea de lo comunicativo, en las consideraciones de los anteriores autores, no menos relevante es la idea de visibilización de esta comunicación, cuyo significado en la organización está destinada a generar evocaciones emocionales en la esfera pública y de esta manera ampliar el eco participativo junto con otros.

Es por ello que una las consignas de la organización que pregonan en el plantón dice: "No más secuestros ni desapariciones, ven, haz algo, di algo para que no te toque a ti" (P5 84:84). La consigna es una interpelación ante los otros que circundan el plantón, para que sumen con la voz y la acción: "ven, haz algo, di algo," los hacen participes evocando nuevamente el acontecimiento trágico que cierne a la cuidad.

Explorando la performatividad, en este caso, a partir del drama de la tragedia griega, cabe la pregunta: ¿El acontecimiento trágico del que se habla es de prevenir a los otros de nuevas desapariciones en la polis?, ¿No era este una de las funciones de la obra trágica? A juicio de Orsi (2007) la tragedia opera de lo individual a lo general: “Así es por tanto posible que la tragedia suscite piedad y temor en los espectadores: lo que ocurre a un individuo no puede ser pasado por alto por el resto" (p.52). De esta manera en lo público se cuece una relación afectiva, un sentimiento de apegos (e incluso de desapegos) a determinado espacio a partir de las experiencias y las memorias de lo vivido (Garcia, 2008; Jelin, 2011).

Es por ello, que lo que sobresale en la participación de la organización es la sensorialidad que tiñe lo público. La expresión de lo sensorial, traída Rancière citada por Arcos (2009), se basa en la noción de la redistribución de lo sensible en el espacio común que afecta no solo al espacio y al tiempo, sino a quien funge de espectador, el cual se ve implicado en un lugar ya no pasivo. El plantón termina frente a su público con una de las consignas dada por la pregonera: "Los queremos vivos, libres y en paz" (P2 92: 92).

De esta manera los transeúntes que pasan frente al plantón se ven impelidos por las voces de las consignas, se detienen, observan y se vuelven participación del plantón. Rancière le da preponderancia a mediar esta distancia y dimensiona un teatro y una pedagogía donde se disminuya la ignorancia ante el conocimiento: "Es necesario un teatro sin espectadores, donde los asistentes aprendan en lugar de ser seducidos por las imágenes, donde devengan participantes activos en lugar de ser voyeristas pasivos" (Arcos - Palma, 2009, p.151). La posición del espectador es de emancipación, ya que es activo ante el conocimiento que le provee la obra.

\section{Historias de un Álbum familiar}

La aparición del plantón está provista de las consignas ya mencionadas y de las fotografías de los familiares desaparecidos captadas en el tiempo. Allí, rememorar es traer del pasado un presente, con una esperanza máxima de espera que potencia una idea futura de encuentro ó de saber sobre la vida del ser querido ausente. "Pero uno esta con la mente en otra parte que esa es en la mente de los hijos, el hijo que está perdido, que no ha llegado o que quizás de pronto llegue, pero ya es muy difícil” (P4 18: 18). 
La acción vista, expuesta y escuchada en lo público, teje un horizonte abierto entre los participantes, una realidad que transvasa las dimensiones temporales. El presente, cuando la madre que habla refiere la presencia ausencia ante otros en posible alteridad; el pasado, en la conmemoración de lo sucedido y la memoria colectiva de los acontecimientos de la comunidad. Y, por último, el futuro como potencia proyectada cada vez que se congregan (Vargas, 2009, p.101).

Lo que viene a cuento, es la resonancia del tiempo como efecto de la acción en lo público, acción que es narrada, y en ella se escenifican las dimensiones del tiempo. En relación con esto Blair (2002), refiere: "Es entonces en la narración donde se conjugan y se expresan la temporalidad de la memoria. Esta no narra los acontecimientos de una forma unilineal, sino que más bien toma la forma de la temporalidad del relato" (p.25). Lo anterior es apreciable en la siguiente fotografía relatada: "y esta señora ahí se nota inmediatamente que, no ha calmado el dolor la ausencia de su hijo” (P11 132: 132).

Con perspicacia Barthes afirma: la fotografía no dice (forzosamente) lo que ya no es, sino tan sólo y sin duda alguna lo que ha sido. (p. 149). Por ello la fotografía toma la vía cuando menos nostálgica, de significados que consisten en ratificar lo que ella misma representa: Una presencia, la cual entre las madres ha derivado en la invención del álbum (como se señalara más adelante) y en él la autentificación de los lazos de familia, sin embargo, lo constativo no está en el objeto de la fotografía sino en el tiempo (Barthes, 1989, p. 155). Lo anterior se aprecia en la siguiente fotografía relatada: "con estas fotos me encantaría porque es que la realidad esto es lo que nos queda a nosotras en la memoria" (P7 143: 143).

Otro aspecto analizado partir de la fotografía del plantón donde las madres fijan como puctum la imagen de un álbum familiar que les permite transitar entre lo privado y lo público: "todas estas fotos tan bonitas como hiciéramos para hacer un álbum de ellas, como hiciéramos para hacer un álbum para que ellas las tengan aquí y que se hizo y que fue todo lo que se hizo aquí" (p7 143:143).

Se aprovecha lo comentando en Barthes y su reflexión acerca de la fotografía familiar, cuando este anuncia que el linaje que puede advertirse en las fotografías de este tipo, producen una identidad más fuerte que la identidad civil, en tanto pensar los orígenes posibilita mayor tranquilad en el futuro. Se constata de forma similar en el trabajo fotográfico de Abad Colorado, sobre las familias con experiencia de violencia. Ponce de León (2015), sobre esta experiencia del fotógrafo menciona: "La expresión corporal, la manera como se entrelazan los cuerpos parece sugerir que los vínculos familiares son el único patrimonio que queda después de perder bienes, tierras, dignidad y esperanza” (p. 47).

\section{Conclusión}

\section{Teatralidad en el plantón: Antígonas de la Candelaria y la sabiduría política}

Esta última reflexión se presenta dotada con la mayor significación, en tanto se expresa como categoría emergente creada en los ritmos interpretativos con las demás fuentes categoriales. La pregunta inicial, por la compresión de los sentidos y significados que las madres han construido sobre su participación en el escenario público, en este caso en el plantón, llega a tener luces en la medida en que se ha desarrollado una lectura estética, asumiendo un escenario perfomativo, tras la recreación del antiguo teatro ateniense, en cuya acción pública es posible reconocer la llamada redistribución de lo sensible (Ranciere, 2014), la cual no es más que lo común y lo compartido de las voces que se escenifican en los rostros y relatos de las participantes. 
Un reparto de lo sensible fija al mismo tiempo algo común repartido y ciertas partes exclusivas. Esta repartición de las partes y de los lugares se basa en un reparto de espacios, de tiempos y de formas de actividad que determina la forma misma en la que un común se presta a la participación y done unos y otros son parte de ese reparto $(p, 19)$.

De esta manera, acción pública, política y teatro se enlazan, y recobran el planteamiento Arendtiano ya insistido, pero que teje un hilo conductor: la acción como discurso, en tanto pueda ser obrado en el entre nos y en el espacio de aparición, es decir en el espacio público. Para Arendt (2005)

Dichos intereses constituyen, en el significado más literal de la palabra, algo del inter_ est que se encuentra entre las personas y por lo tanto puede relacionarlas y unirlas" y seguidamente dice" La mayor parte de la acción y del discurso atañe a este intermediario, que varía según cada grupo de personas (...) (p.211)

Y remata Arcos - Palma: "Una comunidad del sentir, en términos de Rancière es sin duda alguna aquella que hace posible considerar el arte una parte fundamental de la estructura social" (ArcosPalma, 2009, p.146).

El teatro de la época, entonces, es una comunidad del sentir, tal como fue percibido y descrito en la categoría inicial de afectos y rostros compartidos, a partir de lo registrado en las fotografías relatadas del plantón. Resulta cuanto menos llamativo que este escenario, en particular, muestra la experiencia trágica que atraviesa la experiencia de la Madres de la Candelaria, y acontece como una afección emotiva, la gran pérdida de los lazos familiares y la eminencia de la muerte puesta en los cuerpos, lo que tiene inmediata articulación con una función del género trágico. La exposición de las pasiones humanas. Al decir de Orsi (2007)

En muchas ocasiones el poeta reflexiona y hace reflexionar a su público sobre otras cuestiones referentes non tanto a la vida política como a la existencia trágica del individuo en todas las esferas de la vida, pero en todo caso dicha reflexión tiene lugar sobre la arena del teatro y de forma pública. (p.35)

Es sin lugar a dudas el Mito de Antígona, tragedia que aparece obcecadamente, y como diría Barthes (1980), mito como un sistema de comunicación y mensaje que no tiene objeto en sí, sino una significación, una forma. Perfomatividades entonces, que derivaron a las lecturas estéticas y, a su vez, significados a la experiencia de la participación de las madres. La primera de ellas, la denominada teatralidad en el plantón, lugar donde se asoció la historia de la heroína trágica, partiendo del reconocimiento de que Las Madres de la Candelaria, como organización, realizan una práctica de apoyo mutuo no solo para reconocer un dolor colectivo si no para instalar una denuncia que funge en lo público un acontecimiento que devela la función trágica: Un fenómeno político en la vida de la polis, que requiere un carácter critico respecto al tipo de sociedad y los valores que se han construido en ella.

Luego, la segunda performatividad que se configura en la escena del plantón, cuando las madres exhiben colgadas en sus pechos las fotografías de sus familiares, da paso a hablar de las Antígonas de la Candelaria, ya que no es la importancia del individuo la que se expresa, sino la connotación irreductible del linaje que se hace visible por la forzosa desaparición, y que es reclamada como ley de sangre. Particular coincidencia que se esgrime en el mito de Antígona, cuando la heroína deriva sus obligaciones de los vínculos familiares. La philia que une a Antígona y su hermano, y a las Madres del plantón con sus hijos, no se cancela ni con la muerte toda vez, que las relaciones fraternales no se eligen, sino que vienen dadas por el hecho natural de haber compartido un útero. 
Las acciones públicas de las madres reclamando los cuerpos de sus seres queridos, reflejan la ruptura de los lazos de familia que debe trasgredir el oikos, como ámbito privado, y salir a la esfera pública como única vía superviviente de la familia.

Como dice Longoni (2010) hay un paso de lo íntimo a lo público, cuando al portar la fotografía en los pechos se reivindica la importancia del lazo familiar entre el ausente y quien exhibe su retrato. Es más, y aquí se vuelve ovillando los hilos interpretativos del albúm familiar familiar, categoría que permitió advertir la importancia del tiempo al decir de Ricouer (2006), es lo que pasa y escapa, y, por otra parte, lo que dura. Para luego Barthes (1989) sintetizar: "La fotografía no dice (forzosamente) lo que ya no es, sino tan sólo y sin duda alguna lo que ha sido” (p.149). Esto, para la experiencia del plantón suscita una historia contada, no como aspecto del pasado sino un flujo de tiempo, una distensión entre lo que paso, lo que está pasando, presente, y expectancia de futuro.

Existen razones que permiten, al conjugar la historia de la heroína y las madres del plantón, exponer la idea de sabiduría política. Pero, ¿Qué cabe entender por tal expresión? Para ello concentremos la idea de exhortación délfica, conocerse a sí mismo, su propio interior y de allí los propios límites. Lo anterior no es más que el concurso de la felicidad, vista como sabiduría en tanto aquella, no puede prescindir del conocimiento.

Lo que saltaría a la vista, y con lleva a configurar dicha sabiduría, es la relación de una visión trágica de mundo y de hombre, ambas yacen en una comunidad sentido de la acción que desborda las singularidades para hallar sentidos con los mundos diferentes al propio. El primer sentido, el participativo, supone una conciencia del lugar que se ocupa en una determinad sociedad y una voluntad para actuar en consecuencia. Antígona, así como las madres hacen prevalecer la philia, sentimiento compartido $y$ derivado de los lazos familiares, sus lugares femeninos como reproductores y trasmisora de las tradiciones debe ser defendida en lo público para mantener la vigencia de la supervivencia familiar por encima de las leyes de la ciudad. Pero por ser de orden familiar no dejan de tener carácter político. Su vigor está en la naturaleza pública de su demanda por encima de su propia protección, la cual por tradición ha reposado en el hogar.

De allí la importancia del espacio público, siendo el lugar de encuentro y expresión ciudadana por excelencia (Rizzo, 2010). Se recuerda que la orchestra: "era, en últimas, un espacio semejante a otros espacios vacíos de la ciudad, habilitados por la reflexión, para la palabra interrogada del ciudadano de la polis democrática". (Vélez \& Fuentes 2015, p. 64). Allí Antígona fue presentada públicamente, tal como el atrio de la iglesia de la Candelaria es la orchestra contemporánea en que las madres desarrollan el plantón, ambos escenarios se entienden no solamente como un espacio de circulación e interacción, sino como un espacio político. (Fernández, 2013)

Se amplía la noción de orchestra, con la descripción del profesor Vélez (2015). No sobra indicar que la orchestra es la parte central del teatro, cuya huella arquitectónica se remontaba hasta los tiempos de la antigua ágora, donde trascurría la vid social más intensa de los ciudadanos ( en particular, las actividades de mercado, trato social y diálogo político). (p.49)

En el mito aparece:

ANTÍGONA: ¿Me ayudarás a levantar el cadáver?

ISMENA: Pero ¿de verdad piensas darle sepultura, a pesar de que se haya prohibido a toda la ciudad? 
ANTÍGONA: Una cosa es cierta: es mi hermano y el tuyo, quiéralo o no. Nadie me acusará de traición por haberlo abandonado.

ISMENA: ¡Desgraciada! ¿A pesar de la prohibición de Creonte?

ANTÍGONA: No tiene ningún derecho a privarme de los míos. (Sófocles, 2001, pp. 4-5)

Y, en uno de las fotografías relatadas una de las participantes expresa: "A no yo ya quité el miedo, primero a mí me daba miedo el esposo mío me decía amor se va a hacer matar y yo le decía pues que se le hace si me muero me muero buscando lo mío" (P13 33:33).

En ambos relatos, es similar la construcción de un sujeto que trasiega de un cuerpo individual para acceder al mundo y producir una acción sobre él. El mundo concreto de Antígona se abandona en su condición de hermana de Polinicies, pero al tiempo, y tal como sucede con la expresión de la participante, se abandona en la muerte, el marido, el hijo, el pariente y pasan al dominio de la Polis. Y cuanto menos llamativo recordar a Marguerite Yourcenar (2012), para este caso: "No descansaré hasta verlo reposar en una noche más definitiva que la ceguera humana, acostado en el lecho de las Furias que se trasforman inmediatamente en diosas protectoras, pues todo el dolor al que uno se abandona acaba por convertirse en serenidad" (p.66).

El segundo sentido, hace relación con el rompimiento de la estructura tradicional de la Polis. La distinción entre lo domestico y lo público se trasgrede, como se devela con la participación pública de Antígona y las Madres y el natural oikos se abre para repensar ese nuevo sujeto que nace en, se legitima ante los demás en tanto pone en discurso su acción. De esta manera una nueva forma de acción cobra performatividad en los lenguajes que invocan afectividad, y en consecuencia la confluencia de la que es capaz la sensibilidad humana. Se recuerda aquí, una de las expresiones del pregón de las madres de mayor resonancia en el plantón: "No más secuestros ni desapariciones, ven, haz algo, di algo para que no te toque a ti" ven, haz algo, di algo (P5 84:84).

La historia de Antígona y de las Madres, está constituida por relatos en los que tiene lugar la reconstrucción del sentido de la acción, además por apropiación simbólica de los espacios físicos, que terminan siendo construcciones sociales compartidas (Minor \& Gómez, 2006), allí, el sujeto puede revelarse ante la luz pública; si se le niega esta posibilidad, se le coarta a la persona lo más propio de su ser personal (Vargas, 2009, p.94).

En suma, se considera en este estudio que Antígona ilustra la práctica del plantón veinticuatro siglos después de haberse escrito; una mujer desafió en el Ágora de Tebas públicamente los mandatos de Creonte, y un grupo de mujeres en la actualidad denuncian y reclaman los cuerpos de sus seres queridos. Ambas, en una especie de anacronía de sus relatos, enfrentan y movilizan los espectadores de la ciudad, lo que puede ser leído como una acción colectiva que agendada en lo público (Murcia y Granada, 2015), propone que la experiencia y el mundo concreto de sus pérdidas, devenga en una visión trágica que ayuda develar su sentido de particularidad, quién soy, saliendo al encuentro público donde se encuentran las acciones de los otros con sus mundos diferentes. Así, una posible sabiduría política, dispuesta por el mandato délfico significa, todo lo más, la estética que envuelve la participación en el plantón de las Madres de la Candelaria. 


\section{Referencias bibliográficas}

Arcos, R. (Octubre 2009). La estética y su dimensión política según Jacques Ranciére. Nómadas, (31), pp. 139-155.

Arendt, H. (2005). La Condición Humana. Introducción de Manuel Cruz. Buenos Aires, Argentina: Paidos.

Atkinson, P., y Delamont, S. (2015). Perspectivas analíticas. En N. K. Denzin y Y. S. Lincoln. (Ed.), Métodos de recolección y análisis de datos: manual de investigación cualitativa volumen IV (pp. 369-408). Barcelona, España: Gedisa Editorial.

Barthes, R. (1989). La cámara lucida: notas sobre la fotografía. Barcelona, España: Paidós Comunicaciones.

Barthes, R. (1980). Mitologías. México D.F., México: Siglo veintiuno editores.

Barthes, R., Bremond, C., Todorov, T., y Metz, C. (1970). La semiología. Buenos Aires, Argentina: Editorial tiempo contemporáneo.

Blair, E. (Julio-Diciembre, 2002). Memoria y narrativa: La puesta del dolor en la escena pública. Estudios Políticos, (21), pp. 9-28.

Botero, P., Torres, J., y Alvarado, S. (2008). Perspectivas teóricas para comprender la categoría participación ciudadana-política juvenil en Colombia. Revista Latinoamericana de Ciencias Sociales, Niñez y Juventud, 6 (2), p. 565-611

Butler, J. (2011, septiembre). La alianza de los cuerpos y la política de la calle. El estado de las cosas. Transversales. Recuperado de https://goo.gl/9jvFpp

Castrillón, J. E., Villa, J. D. y Marín, A. F. (2016). Acciones colectivas como prácticas de memoria realizadas por una organización de víctimas del conflicto armado en Medellín (Colombia). Revista Colombiana de Ciencias Sociales, 7(2), 404-424. doi: 10.21501/22161201.1779

Centro Nacional de Memoria Histórica. (2013). ¡Basta Ya! Colombia: Memorias de guerra y dignidad. Recuperado de: https://goo.gl/I0BN1e

Colorado, J. (junio-agosto, 2016). Hoy tenemos, mañana no sabemos: La fotografía y la guerra. ArtNexus, (147), pp. 32-36.

Chase, S. (2015). Investigación Narrativa: Multiplicidad de enfoques, perspectivas y voces. En N. K. Denzin y Y. S. Lincoln. (Ed.), Métodos de recolección y análisis de datos: manual de investigación cualitativa volumen IV (pp. 58-112). Barcelona, España: Gedisa Editorial.

Díaz, A. (2003, junio). Una discreta diferenciación entre la política y lo político y su incidencia sobre la educación en cuanto a la socialización política. Reflexión Política. Recuperado de https://goo.gl/gdHYDI

Díaz, A., y Alvarado, S. (2012, julio-diciembre). Subjetividad política encorpada. Revista Colombiana de Educación. Recuperado de https://goo.gl/wG1qBA

Díaz, A., y González, F. (2005, octubre-diciembre). Subjetividad: Una perspectiva histórico cultural. Conversación con el psicólogo cubano Fernando González Rey. Universitas Psychologica. Recuperado de https://goo.gl/hgeqau

Eco, U. (2012). Tratado de semiótica general. México D. F., México: Debolsillo. 
Estrada, C., Vásquez, P., Zapata, D., \& Patiño, C. (2011). Los sentimientos políticos entre jóvenes universitarios de instituciones públicas y privadas de la ciudad de Medellín en el año 2011 (Tesis de pregrado). Universidad San Buenaventura, Medellín, Colombia.

Fernández, R. (2013). El espacio público en disputa: Manifestaciones políticas, ciudad y ciudadanía en el Chile actual. Psicoperspectivas, 12(2), 28-37. doi:10.5027/PSICOPERSPECTIVAS-VOL12ISSUE2-FULLTEXT-278

Finley, S. (2015). Investigación con base en las artes: La realización de una pedagogía revolucionaria. En N. K. Denzin y Y. S. Lincoln. (Ed.), Métodos de recolección y análisis de datos: manual de investigación cualitativa volumen IV (pp. 113- 139). Barcelona, España: Gedisa Editorial.

García, L. (2008). Las Damas de Blanco y la Lucha por el Espacio Público en La Habana. Cuba in transition ASCE. Recuperado de https://goo.gl/v8WHFe

Giraldo, M., Toro, L., Estrada, A., y Mejía, V. (2015). Escuchar, guardar, abrazar: el archivo vivo de la Asociación Caminos de Esperanza Madres de La Candelaria. Medellín, Colombia: Alcaldia de Medellín.

Gómez, J; Minor, F. (2006, enero-febrero). La apropiación del espacio público: las megas marchas y el mega plantón del movimiento postelectoral 2006. El Cotidiano. Recuperado de https://goo.gl/mk53aa

Granada, J., y Murcia, J. (2015). Acción colectiva en la formación de agendas de la política pública de desplazamiento forzado en Medellín. Estudios Políticos. Recuperado de https://goo.gl/HFhbcO

Guiraud, P. (1972). La semiología. México D.F., México: Siglo veintiuno editores.

Harper, D. (2015). ¿Cuáles son las novedades visuales? En N. K. Denzin y Y. S. Lincoln. (Ed.), Métodos de recolección y análisis de datos: manual de investigación cualitativa volumen IV (pp. 235-261). Barcelona, España: Gedisa Editorial.

Ibarra, M. (2011, junio). Acciones colectivas de mujeres por la verdad, la justicia y la reparación. Reflexión Política. Recuperado de https://goo.gl/QBcEri

Jelin, E. (2011). Subjetividad y esfera pública: el género y los sentidos de familia en las memorias de la represión. Política y Sociedad, 48 (3), 555-569. doi:org/10.5209/rev_POSO.2011.v48.n3.36420

Martinez, J. (2010). Movilización femenina en América Latina: el caso de las Madres de la Candelaria - línea fundadora. (Tesis doctoral). Recuperado de: file://C:/Users/USR/Downloads/158941587021-2-PB.pdf

Molina, N. (2005, diciembre). Resistencia comunitaria y transformación de conflictos. Reflexión Política. Recuperado de https://goo.gl/LCEN4X

Nieto, J. (2014). Diéguez, Ileana. (2013) Cuerpos sin dolor. Iconografías y teatralidades del dolor. Córdoba: Documenta/Escénicas. Estudios Políticos. Recuperado de https://goo.gl/Hn1Oea

Longoni, A. (2010). Fotos y siluetas: Políticas visuales en el movimiento de derechos humanos en Argentina. Afterall Journal. Recuperado de https://goo.gl/KBAzCz

Luna, J. R. (2009, mayo). Foto-etnografía llevada a cabo por personas en situación de pobreza en la frontera norte de México. FQS Forum: Qualitative Social Research Sozialforschung. Recuperado de https://goo.gl/HsxTtm 
Orsi, R. (2007). El saber del error: filosofía y tragedia en Sófocles, Cap. Filosofia y literatura (pp. 21 27). Madrid, España: Plaza y Valdez Editores.

Orsi, R. (2007). El saber del error: filosofía y tragedia en Sófocles, Cap. La tragedia y la vida política ateniense (pp. 33-79). Madrid, España: Plaza y Valdez Editores.

Orsi, R. (2007). El saber del error: filosofía y tragedia en Sófocles, Cap. La ceguera (pp. 199-249). Madrid, España: Plaza y Valdez Editores.

Orsi, R. (2007). El saber del error: filosofía y tragedia en Sófocles, Cap. La memoria es olvido (pp. 335-381). Madrid, España: Plaza y Valdez Editores.

Parisí, E., y Cuello, M. (Enero-abril, 2012). Participación política, manifestaciones culturales y mecanismos de resistencia. Psicología Política, 12(23), pp. 41-58.

Ponce de León, C. (2015). Jesús Abad Colorado: Mirar de la vida profunda A gaze at life profound. Bogotá, Colombia: Editorial Planeta Colombiana.

Ranciére, J. (2014). El reparto de lo sensible: Estética y política. Buenos Aires, Argentina: Prometeo libros.

Rizzo, P. (2010). El espacio público de la ciudad Mendoza (Argentina), espacio de disputa y expresión ciudadana. Acme, 9(2), pp. 164-190.

Rodríguez, I. (2007). Vertebración social y concienciación política a través de estrategias artísticas. El plantón del Distrito Federal (2006). Revista Chilena de Antropología Visual, (9), pp. 145-166.

Sabucedo, J., Durán, M., Alzate, M., y Barreto, I. (Enero-Abril, 2011). Emotions, ideology and collective political action. Universitas Psychologica, 10(1), pp.27-34.

Sánchez, E. (2013). Las disputas por la memoria. Las víctimas y su irrupción en la esfera pública. Medellín 2004-2010. Estudios Políticos, (42), pp. 61-84.

Silva, S. (2005). Antígona y la visión trágica del mundo (tesis de pregrado). Universidad Industrial de Santander, Bucaramanga, Colombia.

Strauss, A., y Corbin, J. (2002). Base de la investigación cualitativa: Técnicas y procedimientos para desarrollar la teoría fundamentada. Medellín, Colombia: Editorial Universidad de Antioquia.

Sófocles. (2001). Antígona. Recuperado de https://goo.gl/7y3XZp

Tamayo, A. (2013). Movimientos sociales de mujeres en el conflicto armado colombiano: política participativa y periodismo. Reflexiones en torno al caso de las Madres de la Candelaria. Comunicación y medios. Recuperado de https://goo.gl/wOICbT

Tello, N. (2003). Cornelius Castoriadis y el imaginario radical. Madrid, España: Campo de ideas.

Vargas, J. (Diciembre, 2009). El concepto de acción política en el pensamiento de Hannah Arendt. Eidos: Revista de filosofía de la Universidad del Norte, (11), pp. 82-107

Vasilachis, I. (2015). Investigación cualitativa: proceso, política, representación, ética. En N. K. Denzin y Y. S. Lincoln. (Ed.), Métodos de recolección y análisis de datos: manual de investigación cualitativa volumen IV (pp. 11-42). Barcelona, España: Gedisa Editorial.

Vasilachis, I. (2015). Métodos de recolección y análisis de datos. En N. K. Denzin y Y. S. Lincoln. (Ed.), Métodos de recolección y análisis de datos: manual de investigación cualitativa volumen IV (pp. 43-57). Barcelona, España: Gedisa Editorial.

Vélez, M. (2011). Dar acogida (El motivo de la hospitalidad en la Telemaquia de Homero). Medellín, Colombia: Fondo editorial Universidad EAFIT. 
Vélez, M., y Fuentes, L. (2015). La casa de Dioniso: un estudio sobre el espacio escénico en la Atenas clásica. Medellín, Colombia: Fondo editorial Universidad EAFIT.

Vicente, K. (2008). Roland Barthes. En V. Zecchetto. (Ed.), Seis semiólogos en busca del lector (pp. 81-144). Buenos Aires, Argentina: La Crujía.

Vicente, K. (2008). Umberto Eco. En V. Zecchetto. (Ed.), Seis semiólogos en busca del lector (pp. 191-239). Buenos Aires, Argentina: La Crujía.

Villa Gomes, J., \& Insuasty Rodriguez, A. (2016). Entre la participación y la resistencia: reconstrucción del tejido social desde abajo, más allá de la lógica de reparación estatal. El Agora USB, 16(2). Obtenido de http://revistas.usb.edu.co/index.php/Agora/index

Yourcenar, M. (2012). Fuegos. Bogotá, Colombia: Punto de lectura. 